\title{
Lack of Variation in Inflammatory Hematological Parameters between Benign Nodular Goiter and Papillary Thyroid Cancer
}

\author{
Selçuk Yaylacı ${ }^{1 *}$, Onder Tosun², Orhan Sahin ${ }^{2}$, Ahmet Bilal Genc $^{3}$, Ercan Aydın', \\ Gokhan Demiral ${ }^{5}$, Fatma Karahalil ${ }^{6}$, Serdar Olt $^{3}$, Hasan Ergenç ${ }^{3}$, Ceyhun Varim ${ }^{3}$
}

\begin{abstract}
Background: Inflammatory hematological parameters like the neutrophil/lymphocyte (N/L) ratio have been investigated in many cancer types and significant relationships found with prognosis, for example. The aim of this present study was to investigate the impact of hematological parameters notably on N/L ratio and mean platelet volume (MPV) in papillary thyroid cancer cases. Materials and Methods: A total of 79 patients who underwent a thyroidectomy operation in Findıkl, Goiter Research and Treatment Center during 20112015 period were enrolled in the study, 41 with papillary thyroid cancer and 38 with benign goiter confirmed by pathological examination. We collected clinical and laboratory data for the patients from hospital records retrospectively. Blood samples taken at admission were assessed for parameters compared between the groups. Results: No significant differences between papillary thyroid cancer and benign goiter groups were apparent in terms of age, the N/L ratio, MPV, white blood cell count (WBC), red blood cell count (RBC), hemoglobin, hematocrit, platelet, neutrophil, lymphocyte, red blood cell distribution width (RDW) and platelet crit (PCT) levels ( $>>0.05)$. Only the level of platelet distribution width (PDW) significantly differed, being lower in the papillary cancer group $(p<0.05)$. Conclusions: No significant relationship between papillary thyroid cancer and inflammatory hematological parameters including in particular the N/L ratio and MPV. The relevance of the PDW values remains unclear.
\end{abstract}

Keywords: N/L ratio - MPV - PDW - papillary thyroid cancer - benign nodular goiter

Asian Pac J Cancer Prev, 17 (4), 2321-2323

\section{Introduction}

Increased neutrophil lymphocyte ratio $(\mathrm{N} / \mathrm{L}$ ratio) values and mean platelet volume (MPV) values are associated with inflammatory diseases (Gasparyan et al., 2011; Guthrie et al., 2013), whereas in the noninflammatory diseases $\mathrm{N} / \mathrm{L}$ ratio values are in normal range (Olt et al., 2015).

There are many studies demonstrated that increased $\mathrm{N} / \mathrm{L}$ ratio and increased MPV values were significantly related with the certain types of cancers which were considered as inflammatory diseases.

In this present study, we aimed to investigate relationship between papillary thyroid cancer and various hematological parameters consist of N/L ratio, MPV, white blood cell counts (WBC), red blood cell count (RBC), hemoglobin, hematocrit, platelet, neutrophil, lymphocyte, red blood cell distribution width (RDW) and platelet crit (PCT) levels and platelet distribution width (PDW).

\section{Materials and Methods}

This is a retrospective study. The institutional ethical clearance was obtained before the study. 113 patients who underwent a thyroidectomy operation in Findıklı, Goiter Research and Treatment Center during 2011-2015 period were retrospectively scanned/screened.

As the result of the screening process, 79 patients in conformity with the criteria for being incorporated into the study were identified. 41 patients with papillary thyroid cancer and 38 patients with benign goiter which are confirmed with the pathological examination were enrolled in this study between the years 2011 and 2015. We collected clinical and laboratory features of the patients from hospital records retrospectively. We collected patients' blood samples at the admission and then we compare these parameters between the groups. The hemogram parameters were studied through Mindray BC-3200 device. 
Table 1. Comparison of the Hematological Parameters between the Patients with Papillary Thyroid Cancer and Benign Nodular Goiter

\begin{tabular}{|c|c|c|c|}
\hline $\begin{array}{c}\text { Parameters } \\
\mathrm{n}=79\end{array}$ & $\begin{array}{c}\text { Patients with papillary } \\
\text { thyroid cancer } n=41\end{array}$ & $\begin{array}{l}\text { Patients with benign nodular } \\
\text { goiter } n=38\end{array}$ & $P$ values \\
\hline $\mathrm{WBC}(\mathrm{K} / \mathrm{uL})$ & $6758 \pm 1682$ & $6344 \pm 1914$ & 0.310 \\
\hline $\mathrm{RBC}(\mathrm{M} / \mathrm{uL})$ & $4.6 \pm 0.4$ & $4.8 \pm 0.4$ & 0.069 \\
\hline Hemoglobin (g/dl) & $12.9 \pm 1.6$ & $13.5 \pm 1.4$ & 0.104 \\
\hline $\mathrm{HCT}(\%)$ & $39 \pm 4.1$ & $40.6 \pm 4.5$ & 0.103 \\
\hline Platelets (K/uL) & $264 \pm 52$ & $258 \pm 72$ & 0.663 \\
\hline MPV (fl) & $9.1 \pm 1.3$ & $9.0 \pm 1.1$ & 0.697 \\
\hline Neutrophil (K/uL) & $4026 \pm 1296$ & $3723 \pm 1630$ & 0.362 \\
\hline Lymphocyte (K/uL) & $2190 \pm 546$ & $2142 \pm 583$ & 0.706 \\
\hline $\mathrm{N} / \mathrm{L}$ ratio & $1.9 \pm 0.7$ & $1.8 \pm 0.9$ & 0.750 \\
\hline RDW-CV & $14.1 \pm 1.6$ & $141 \pm .2$ & 0.827 \\
\hline PDW $(\%)$ & $15.4 \pm 1.7$ & $16.3 \pm 1.2$ & 0.013 \\
\hline PCT $(\%)$ & 0.2 & 0.2 & 0.643 \\
\hline
\end{tabular}

The patients were divided into two groups as 41 $(51.9 \%)$ cases diagnosed with papillary thyroid cancer and 38 cases diagnosed with benign goiter $(48.1 \%)$.

\section{Criteria for Those Incorporated into the Study}

The patients aged between 17-70, who underwent thyroidectomy in our hospital and whose data were complete, were incorporated into the study.

Exclusion Criteria: The patients with diabetes, acutechronic infection, cancer anamnesis in their medical history, renal failure, liver disease, and a hematological disease as well those who had medical records as to the use of anticoagulants, steroids, alcohol along with those with a medical history of hepatitis, and the patients whose TSH levels were not normal were all excluded from the study. In our study, 33 patients were excluded due to the criteria in question and 1 patient was excluded from the study due to his incomplete data.

\section{Statistical analysis}

The statistical analysis was performed by using SPSS 18.0 computer program. The categorical variables were expressed in the form of numbers or percentages, whereas the continuous variables were represented by mean \pm standard deviation. In the comparison of continuous variables, the compliance of the parameters with the normal distribution was examined through KolmogorovSmirnov test in the first place. The independent sampling T-test was used in comparing the data complied with the normal distribution

\section{Results}

Some $41(51.9 \%)$ out of 79 thyroidectomized patients incorporated into the study (male/female: 17/62 -21.5\% / 78.5\%) had papillary thyroid cancer, while 38 of them $(48.1 \%)$ had benign goiter. There weren't significant difference between patients with papillary thyroid cancer and the patients with benign nodular in terms of age, neutrophil lymphocyte ratio (N/L ratio), mean platelet volume (MPV), white blood cell counts (WBC), red blood cell count (RBC), hemoglobin, hematocrit, platelet, neutrophil, lymphocyte, red blood cell distribution width (RDW) and platelet crit (PCT) levels ( $>>0.05)$. However there was significant relationship between the level of platelet distribution width (PDW) and papillary thyroid cancer and it was significantly lower in papillary cancer group $(\mathrm{p}<0.05)$.

Results have been summarized in Table 1.

\section{Discussion}

Thyroid nodules are seen more frequently in clinical and radiological practice. In recent years, the differentiated thyroid cancer (DTC) has become widespread in the world (Haugen et al., 2016). So far, the epidemiologic studies have demonstrated that the frequency of the palpable thyroid nodules are 5\% in females, and $1 \%$ in males who continue their lives in iodine-sufficient regions in the world (Vander et al., 1968; Tunbridge et al, 1977). The exclusion of thyroid cancer is the main issue to be dealt with in terms of clinical significance of the nodules. This situation is observed in $7-15 \%$ of nodules and it is depending on the ages, genders and past exposure to radiation, family history, and similar other factors of the patients (Hegedus et al., 2004; Mandel et al., 2004). DTC are the most frequently observed cancers among all of the thyroid cancer types (Sherman et al., 2003). The most frequent type of the DTC is papillary thyroid cancer.

There are many studies demonstrated that increased neutrophil lymphocyte ratio (N/L ratio) and increased mean platelet volume (MPV) values were significantly related with the certain types of cancers which were considered as inflammatory diseases.

Increased N/L ratio values and MPV values are associated with inflammatory diseases (Gasparyan et al., 2011; Guthrie et al., 2013), whereas in the noninflammatory diseases $\mathrm{N} / \mathrm{L}$ ratio values are in normal range (Olt et al., 2015).

There are many studies demonstrated that increased MPV was significantly related with colon cancer (Li et al., 2014), lung cancer (Kumagai et al., 2015), gastric cancer (Kılınçalp et al., 2014), endometrial carcinoma (Karateke et al., 2015) and in head and neck neoplasms (Eryilmaz et al., 2015). In the literature, increased $\mathrm{N} / \mathrm{L}$ ratio was significantly related with the lung cancer (Kemal et al., 2014), gastric cancer (Kim et al., 2015), colon cancer (Absenger et al., 2013) and papillary thyroid cancer 
(Seretis et al., 2013).

In a study conducted by Kocer et al. they found that the neutrophil lymphocyte ratio (N/L ratio) was higher in patients with papillary cancer than the other groups. In the same study N/L ratio values which was above 1.91 was determined to be more risky in terms of papillary cancer (Kocer et al., 2015). In another study conducted by Seretis et al. they found that elevated N/L ratio associated with papillary thyroid carcinoma (Seretis et al., 2013).

In this present study N/L ratio wasn't significantly different in patients with papillary cancer compared to the control group.

In a study conducted by Baldane et al. they found that increased MPV levels were associated with papillary thyroid cancer. In this present study, MPV levels weren't different between th groups $(\mathrm{p}>0.05)$. In a study MPV level above $7.81 \mathrm{fl}$ was stated to be more risky in terms of papillary cancer (Baldane et al., 2015).

In this present study, mean MPV levels were $9.1 \pm 1.3 \mathrm{fl}$ (>7.81 fl) in patients with papillary cancer. However, mean MPV levels were 9.0 $\pm 1.1 \mathrm{fl}$ in patients with benign goiter and there wasn't statistically significant difference between patients with papillary cancer and patients with benign goiter.

In a study conducted on endometrium cancer by Kurtoglu et al. they found that decreased PDW values were significantly associated with endometrium cancer (Kurtoglu et al., 2015). In this present study decreased PDW levels were significantly associated with papillary thyroid cancer $(\mathrm{p}<0.05)$.

In conclusion, we can say that N/L ratio and MPV aren't useful markers for the papillary thyroid cancer cantrast to the related investigations. PDW could be a marker for papillary thyroid cancer.

\section{References}

Absenger G, Szkandera J, Stotz M, et al (2013). Preoperative neutrophil-to-lymphocyte ratio predicts clinical outcome in patients with stage II and III colon cancer. Anticancer Res, 33, 4591-4.

Baldane S, Ipekci SH, Sozen M, et al (2015). Mean platelet volume could be a possible biomarker for papillary thyroid carcinomas. Asian Pac J Cancer Prev, 16, 2671-4.

Eryilmaz A, Basal Y, OmurluI K (2015). Can head and neck cancers be detected with mean platelet volume? Asian Pac J Cancer Prev, 16, 7045-7.

Gasparyan AY, Ayvazyan L, Mikhailidis DP, et al (2011). Mean platelet volume: a link between thrombosis and inflammation? Curr Pharm Des, 17, 47-58.

Guthrie GJ, Charles KA, Roxburgh CS, et al (2013). The systemic inflammation-based neutrophil-lymphocyte ratio: experience in patients with cancer. Crit Rev Oncol Hematol, 88, 218-30.

Haugen BR, Alexander EK, Bible KC, et al (2016). American thyroid association management guidelines for adult patients with thyroid nodules and differentiated thyroid cancer: the american thyroid association guidelines task force on thyroid nodules and differentiated thyroid cancer. Thyroid, 26, 1-133.

Hegedus L (2004). Clinical practice. The thyroid nodule. N Engl J Med, 351, 1764-71.

Karateke A, Kaplanoglu M, Baloglu A (2015). Relations of Platelet Indices with Endometrial Hyperplasia and
Endometrial Cancer. Asian Pac J Cancer Prev, 16, 4905-8.

Kemal Y, Yucel I, Ekiz K, et al (2014). Elevated serum neutrophil to lymphocyte and platelet to lymphocyte ratios could be useful in lung cancer diagnosis. Asian Pac J Cancer Prev, 15, 2651-4.

Kılınçalp S, Ekiz F, Başar O, et al (2014). Mean platelet volume could be possible biomarker in early diagnosis and monitoring of gastric cancer. Platelets, 25, 592-4.

Kim JH, Han DS, Bang HY, et al (2015). Preoperative neutrophilto-lymphocyte ratio is a prognostic factor for overall survival in patients with gastric cancer. Ann Surg Treat Res, 89, 81-6.

Kocer D, Karakukcu C, Karaman H, et al (2015). May the neutrophil/ lymphocyte ratio be a predictor in the differentiation of different thyroid disorders? Asian Pac J Cancer Prev, 16, 3875-9.

Kumagai S, Tokuno J, Ueda Y, et al (2015). Prognostic significance of preoperative mean platelet volume in resected non-small-cell lung cancer. Mol Clin Oncol, 3, 197-201.

Kurtoglu E, Kokcu A, Celik H, et al (2015). Platelet indices may be useful in discrimination of benign and malign endometrial lesions, and early and advanced stage endometrial cancer. Asian Pac J Cancer Prev, 16, 5397-400.

Li JY, Li Y, Jiang Z, et al (2014). Elevated mean platelet volume is associated with presence of colon cancer. Asian Pac J Cancer Prev, 15, 10501-4.

Mandel SJ (2004). A 64-year-old woman with a thyroid nodule. JAMA, 292, 2632-42.

Olt S (2015). Relationship between thyroid nodules and neutrophil/lymphocyte ratio. Acta Medica Mediterranea, 31, 725-7.

Seretis C, Gourgiotis S, Gemenetzis G, et al (2013). The significance of neutrophil/lymphocyte ratio as a possible marker of underlying papillary microcarcinomas in thyroidal goiters: a pilot study. Am J Surg, 205, 691-6.

Sherman SI (2003). Thyroid carcinoma. Lancet, 361,501-511.

Tunbridge WM, Evered DC, Hall R, et al (1977). The spectrum of thyroid disease in a community: the Whickham survey. Clin Endocrinol, 7, 481-93.

Vander JB, Gaston EA, Dawber TR et al (1968). The significance of nontoxic thyroid nodules. Final report of a 15-year study of the incidence of thyroid malignancy. Ann Intern Med, 69, 537-40. 